\title{
Sex-related differences in the association between waist circumference and bone mineral density in a Korean population
}

\author{
Lian-Hua Cui ${ }^{1}$, Min-Ho Shin ${ }^{2 *}$, Sun-Seog Kweon ${ }^{2,3}$, Jin-Su Choi ${ }^{1}$, Jung-Ae Rhee ${ }^{1}$, Young-Hoon Lee ${ }^{4}$, \\ Hae-Sung Nam ${ }^{5}$, Seul-Ki Jeong ${ }^{6}$, Kyeong-Soo Park', So-Yeon Ryu ${ }^{8}$ and Seong-Woo Choi ${ }^{8}$
}

\begin{abstract}
Background: Large waist circumference is linked to poor health. Investigations of the relationship between waist circumference, as an index of abdominal fat, and bone mineral density (BMD) have yielded inconsistent results. We investigated the association between abdominal obesity measured using waist circumference and BMD in a large-scale population-based study.

Methods: We enrolled 8981 Korean (3592 males and 5389 females) community-dwelling individuals aged $\geq 50$ years from 2007 to 2010. BMD was measured using dual-energy X-ray absorptiometry at lumbar spine and femoral neck skeletal sites. A multiple linear regression analysis was used to evaluate the relationship between waist circumference quartiles and BMD after adjusting for age, height, weight, and regular exercise.

Results: The adjustment for age, height, weight, and regular exercise revealed a negative linear association between quartile of waist circumference and BMD at the femoral neck and lumbar spine sites in males and females. Waist circumference was more strongly correlated with BMD in males than in females. Although the correlations were slightly attenuated following further adjustment for percent body fat, they remained statistically significant.

Conclusions: Our results revealed that waist circumference is independently and inversely associated with BMD after adjusting for age, weight, height, regular exercise and percent body fat, suggesting that waist circumference is a potential predictor of osteoporosis in middle-aged and older Korean males and females.
\end{abstract}

Keywords: Abdominal obesity, Waist circumference, Bone mineral density

\section{Background}

The increasing prevalence of osteoporosis and obesity has created a significant health problem worldwide. The proportion of elderly people in Korea was $7.4 \%$ in 2000 and is expected to reach $15.1 \%$ in 2020 . The public health burden of osteoporotic fractures is expected to rise as the aging population increases. Furthermore, the overall prevalence of obesity (body mass index, (BMI) $>25 \mathrm{~kg} / \mathrm{m}^{2}$ ) in Korean adults increased from 25.8 to $32.8 \%$ between 1998 and 2012. Obesity has a considerable impact on health and increases the risk of several chronic diseases, including insulin resistance,

\footnotetext{
*Correspondence: mhshinx@paran.com

${ }^{2}$ Department of Preventive Medicine, Chonnam National University Medical School, 5 hak-dong, Dong-gu, 501-746 Gwangju City, South Korea Full list of author information is available at the end of the article
}

metabolic syndrome, and type 2 diabetes mellitus. Abdominal obesity is associated with increased all-cause, cardiovascular [1-4], cancer mortality [4-6], and overall mortality. Abdominal fat accumulation may be a predictor of a pro-inflammatory state [7-9], and recent data have demonstrated overlapping pathways between bone biology and inflammatory processes [10-14]. Thus, investigation of the relationship between osteoporosis and abdominal obesity in the aging population is warranted.

Previous studies using BMI as an indicator of overall obesity found that higher BMI was correlated with high bone mass, reductions in body weight were associated with bone loss, and that the positive association between body weight or BMI and bone mineral density (BMD) was related to a weight-bearing effect on bone, leading to the conclusion that obesity was protective against 
fracture [15-17]. However, subsequent studies did not confirm the protective effect of obesity on osteoporosis, with reports of both significant negative [18-22] and positive [23-26] correlations between body weight and bone health. However, central obesity was suggested to be more relevant to bone health than general obesity reflected by BMI; thus, differences in the relationships between surrogate and direct measures of central adiposity and BMD were proposed to underlie the contradictory findings.

Waist circumference is frequently used as a simple, inexpensive measure of central obesity in population-based studies. However, the results of previous investigations of the association between waist circumference and BMD have been inconsistent $[22,23,25,27,28]$. Thus, we investigated the association between abdominal obesity - as measured by waist circumference-and BMD after adjusting for age, height, weight, regular exercise and percent fat in a large-scale population-based study of Korean males and females aged $\geq 50$ years.

\section{Methods}

\section{Subjects}

The Dong-gu Study is an ongoing prospective study designed to investigate the prevalence, incidence, and risk factors for chronic disease in an urban population [29]. To identify potential participants, the national resident registration records were used. From 2007 to 2010, 34,040 eligible subjects aged $\geq 50$ years, and who resided in the Dong-gu district of Gwangju Metropolitan City in South Korea, were invited to participate by mail and telephone. A total of 9,260 subjects were enrolled (response rate: 27.2\%; 3,711 male and 5,549 female). Of those, 9,206 subjects underwent lumbar spine or hip BMD using a Lunar Prodigy bone densitometer (GE, Madison, WI). 9,056 subjects had both lumbar spine and femoral neck BMD. Of those, 75 subjects were excluded because of missing data on waist circumference, anthropometric data and body composition. The final sample consisted of 8,981 individuals (3,592 men and 5,389 men). All participants provided informed consent, and the study was conducted in accordance with the guidelines in The Declaration of Helsinki. The study was approved by the institutional review board of Chonnam National University Hospital.

\section{Anthropometric measurements}

Body weight, lean body mass, fat mass and fat percentage were measured in indoor clothing or light gown without shoes by bioelectrical impedance analysis using a calibrated Inbody 520 (Biospace Co. Korea). Height was measured to the nearest $0.1 \mathrm{~cm}$, and weight was measured in the upright position to the nearest $0.1 \mathrm{~kg}$. Waist circumference was measured with the subject standing, at the level midway between the lower rib margin and the iliac crest. Hip circumference was measured at the fullest point around the buttocks. Waist circumference was divided by hip circumference to calculate waist-to-hip ratio. Regular exercise was categorized as irregular or regular based on the frequency of recreational activity and exercise during a week.

\section{Measurements of bone mineral density}

Participants had their lumbar spine and femoral neck BMD measured by Lunar Prodigy (GE, Madison, WI). The lumbar spine BMD represents the average BMD of L1-L4. Daily phantom scans were performed each morning for proper quality control. All BMD scans were conducted using standardized procedures following the manufacturer's recommended protocols by well-trained examiners. Intrascanner reproducibility of repeated measurements, expressed as coefficient of variation, was less than $1 \%$.

\section{Statistical analysis}

The descriptive data for the major characteristics and the BMD values of the two groups are expressed as the mean \pm standard deviation (SD). We used $t$-tests to determine statistical differences. Waist circumference was divided into sex-specific quartiles. Fractional polynomial regression was used to describe the association between weight, body fat percent, and waist circumference and $\mathrm{BMD}$, and to evaluate the association between waist circumference and BMD after adjusting for age, height, weight, and body fat percent. Multiple linear regression analysis was used to evaluate the relationship between the quartiles of waist circumference and BMD, after adjusting for age, height, weight, and regular exercise in the first model, and further adjusting for body fat percent in the second model. In addition, multiple linear regression analyses were used to evaluate the linear relationship of waist circumference, waist/hip ratio, body fat percent and fat mass with BMD after adjusting for age, height, weight, and regular exercise. Statistical analyses were conducted using Stata version 12 (StataCorp, Texas, USA).

\section{Results}

\section{Characteristics of the study subjects}

Table 1 shows the baseline characteristics of the subjects are shown in. The mean age at baseline was $66.2 \pm 8.0$ years for males and $64.4 \pm 8.2$ years for females. The mean height, weight, and BMI were respectively, $165.9 \pm$ $5.7 \mathrm{~cm}, 65.9 \pm 9.1 \mathrm{~kg}$, and $23.9 \pm 2.8 \mathrm{~kg} / \mathrm{m}^{2}$ for males and $153.2 \pm 5.5 \mathrm{~cm}, 57.8 \pm 8.0 \mathrm{~kg}$, and $24.6 \pm 3.0 \mathrm{~kg} / \mathrm{m}^{2}$ for females. The mean abdominal circumference was $87.1 \pm 7.8 \mathrm{~cm}$ in males and $88.5 \pm 9.0 \mathrm{~cm}$ in females. Waist to hip ratio, percent body fat, and fat mass were significantly higher in females than in males. The mean BMD at the lumbar spine and femoral neck sites was considerably higher in males than females. 
Table 1 Characteristics of the study subjects

\begin{tabular}{llll}
\hline & $\begin{array}{l}\text { Men } \\
(\mathbf{n = 3 5 9 2})\end{array}$ & $\begin{array}{l}\text { Women } \\
(\mathbf{n = 5 3 8 9 )}\end{array}$ & p-value \\
\hline Age (years) & $66.2 \pm 8.0$ & $64.4 \pm 8.2$ & $<0.001$ \\
Height $(\mathrm{cm})$ & $165.9 \pm 5.7$ & $153.2 \pm 5.5$ & $<0.001$ \\
Weight $(\mathrm{kg})$ & $65.9 \pm 9.1$ & $57.8 \pm 8.0$ & $<0.001$ \\
BMl $\left(\mathrm{kg} / \mathrm{m}^{2}\right)$ & $23.9 \pm 2.8$ & $24.6 \pm 3.0$ & $<0.001$ \\
Regular exercise $(\%)$ & $1391(38.7)$ & $1521(28.2)$ & $<0.001$ \\
Abdominal circumference $(\mathrm{cm})$ & $87.1 \pm 7.8$ & $88.5 \pm 9.0$ & $<0.001$ \\
Waist to hip ratio & $0.94 \pm 0.05$ & $0.95 \pm 0.07$ & $<0.001$ \\
Body fat percent $(\%)$ & $25.8 \pm 5.8$ & $35.5 \pm 5.9$ & $<0.001$ \\
Fat mass (kg) & $17.3 \pm 5.5$ & $20.8 \pm 5.7$ & $<0.001$ \\
Lumbar spine BMD $\left(\mathrm{g} / \mathrm{cm}^{2}\right)$ & $1.161 \pm 0.204$ & $0.985 \pm 0.169$ & $<0.001$ \\
Femoral neck BMD $\left(\mathrm{g} / \mathrm{cm}^{2}\right)$ & $0.881 \pm 0.13$ & $0.788 \pm 0.122$ & $<0.001$ \\
\hline
\end{tabular}

Values are mean \pm SD or number (percentage).

$\mathrm{BMI}$, body mass index; BMD, bone mineral density.

Figures 1 and 2 show the fractional polynomial regression of waist circumference by BMD according to sex before and after adjustment for covariates. The bivariate analysis revealed a positive quadratic relationship between waist circumference and BMD with a plateau or slight decline at the higher levels. However, after adjusting for age, height, weight, and percent body fat, we observed a negative quadratic relationship between waist circumference and BMD with an initial incline; thus, the correlation between waist circumference and BMD values shifted from positive to negative after adjusting for the covariates.

\section{Adjusted means of bone mineral density by quartiles of waist circumference}

Table 2 shows femoral neck and lumbar spine BMD according to quartile of waist circumference. We found a negative linear association between waist circumference and BMD at both sites in males and females after adjusting for age, height, weight and regular exercise. Lumber spine BMD was lower in the third and fourth quartiles of waist circumference than in the first quartile in males and females. However, we found no significant difference between the first and second quartiles. Although further adjustment for percent body fat slightly attenuated these associations, they remained significant. We found interaction effects between sex and waist circumference for BMD at the lumbar spine and femoral neck sites $(P=0.001$ and 0.016 , respectively).

\section{Linear association between obesity-related phenotypes and bone mineral density}

Table 3 shows results of linear regression analysis of obesity-related phenotypes with BMD. Significant negative associations of waist circumference, waist/hip ratio, body fat percent and fat mass with BMD were found in both sexes.

\section{Discussion}

We investigated the association between waist circumference as an indicator of abdominal obesity and BMD in a large-scale population-based study of Korean males and females aged $\geq 50$ years. Our results indicated that after adjusting for age, weight, height, regular exercise and percent body fat, waist circumference was negatively associated with lumbar spine and femoral neck BMD in older Koreans, particularly males.

The results of previous investigations of the association between surrogate or direct measures of central adiposity and BMD have been inconsistent. Three previous population-based studies that adjusted for the weightbearing effect of body weight found that the waist-to-hip ratio (WHR) was negatively associated with BMD in the lumbar spine and calcaneus and with bone mineral content (BMC) [18-20], however, another study found a highly significant positive correlation between BMD in the proximal and ultradistal radius and WHR in obese individuals [30]. Moreover, several previous studies investigating the association between direct measures of central adiposity and BMD reported conflicting results. Two studies found that BMD was inversely associated with body-weight-adjusted abdominal fat mass and lean body mass-adjusted abdominal visceral adipose tissue (VAT) [31,32], however, other studies reported positive relationship between abdominal fat distribution,percent truncal fat and bone mass and BMD [33,34].

Some studies assessed the association between waist circumference as a metabolic syndrome components and BMD, but the results are also inconclusive. Three studies found a positive correlation between waist circumference and BMD [23-25], whereas others reported a negative correlation [22,27,28]. Moreover, general population-based studies have found a significant negative correlation between BMD and waist circumference in premenopausal females [35] and in males and females [36].

Several factors may account for these inconsistent results, such as differences in the populations under investigation (age, sex, and ethnicity), in the methods used to measure BMD and central adiposity, in sample size, or in the number and type of covariates controlled for across studies. The inclusion of body weight or BMI as a covariate may itself affect the association between central obesity and BMD. We assessed the relationship between waist circumference and BMD before and after adjusting for age, weight, height, percent body fat, and regular exercise, and found that the correlation changed from positive to negative after adjusting for these covariates. Several previous studies reported a positive correlation between fat mass and hip 


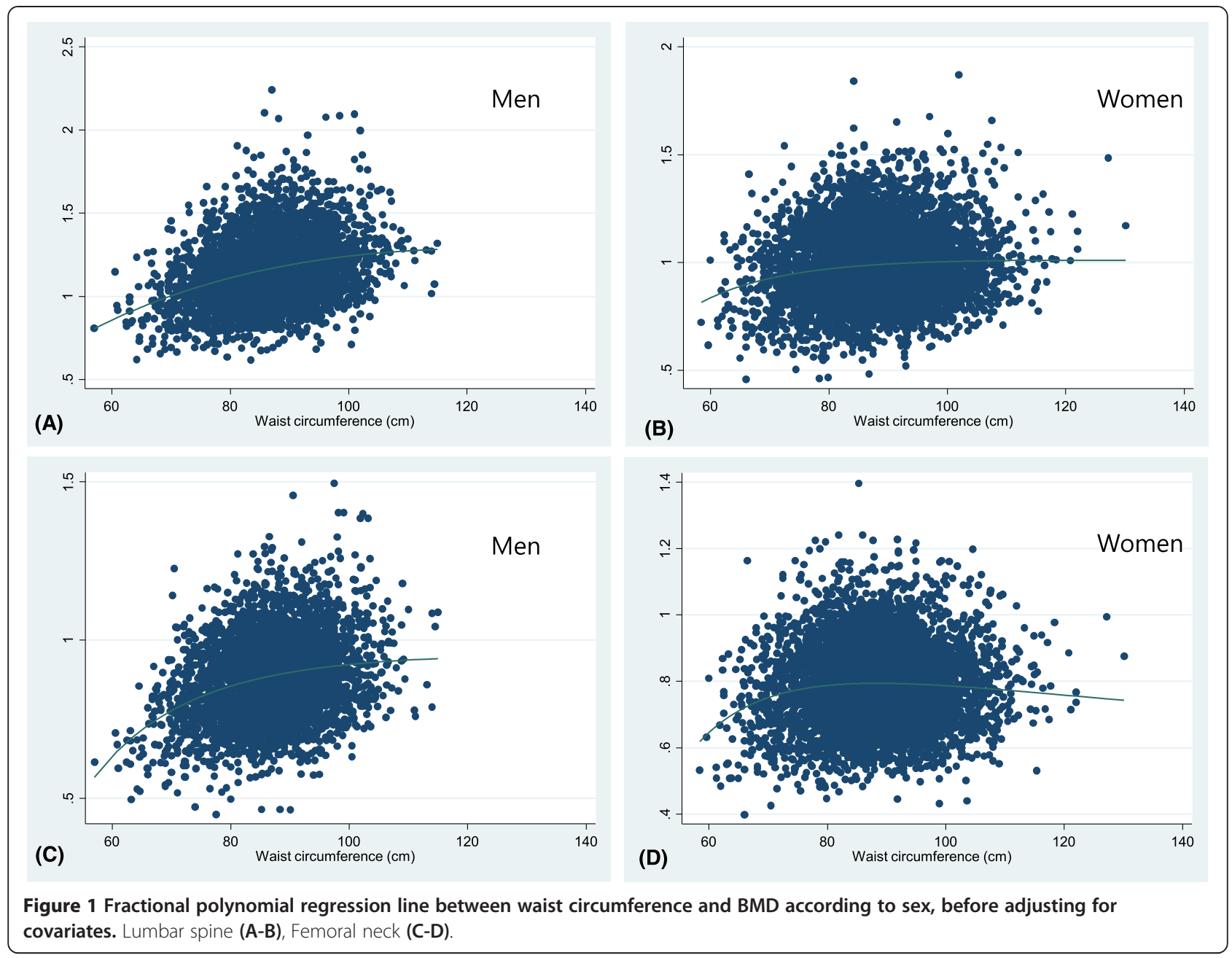

and spine BMD [21,37] or total-body BMC [38] before adjusting for body weight; however, the association was negative after adjusting for body weight. Similarly, two studies in Korean males and postmenopausal females found a negative association between WHR and BMD in the calcaneus [19] or lumbar spine [18] after adjusting for BMI or body weight, whereas a study that did not adjust for body weight found a positive correlation between truncal fat mass and total hip and the femoral neck BMD in healthy premenopausal females [39]. Aghaei Meybodi et al. [40] did not adjust for weight and identified a positive relationship between all anthropometric measures and BMD in both sexes.

A greater body weight is thought to increase skeletal loading, which activates an adaptive response leading to an increase in bone density. Fat mass is a major component of body weight. When the mechanical loading effect of body weight is statistically removed, fat mass is negatively associated with bone. After controlling for age, body weight, height, and regular exercises, we identified a negative correlation between waist circumference and BMD in the femoral neck and lumbar spine in middle-aged and older males and females. Further adjustment for percent body fat slightly attenuated the correlations; however, they remained significant. Our findings suggest that weight-adjusted abdominal fat mass may have non-mechanical loading effects on bone mass and, thus, abdominal obesity may not always protect against osteoporosis. The negative effect of weight-adjusted abdominal fat mass on bone might be driven by higher levels of pro-inflammatory cytokines, which may up-regulate receptor activators of nuclear factor-kB ligand, leading to increased bone resorption and decreased BMD $[41,42]$.

Our results revealed a significant sex-related difference in waist circumference and BMD, such that the negative correlation between waist circumference and lumbar spine and femoral neck BMD was greater in males than in females. The reasons for this are not entirely clear, although hormonal differences may be an important factor underlying this effect. However, sex-related differences in the relationship between body fat and BMD are controversial. Katzmarzyk et al. [32] found no sex-related difference 


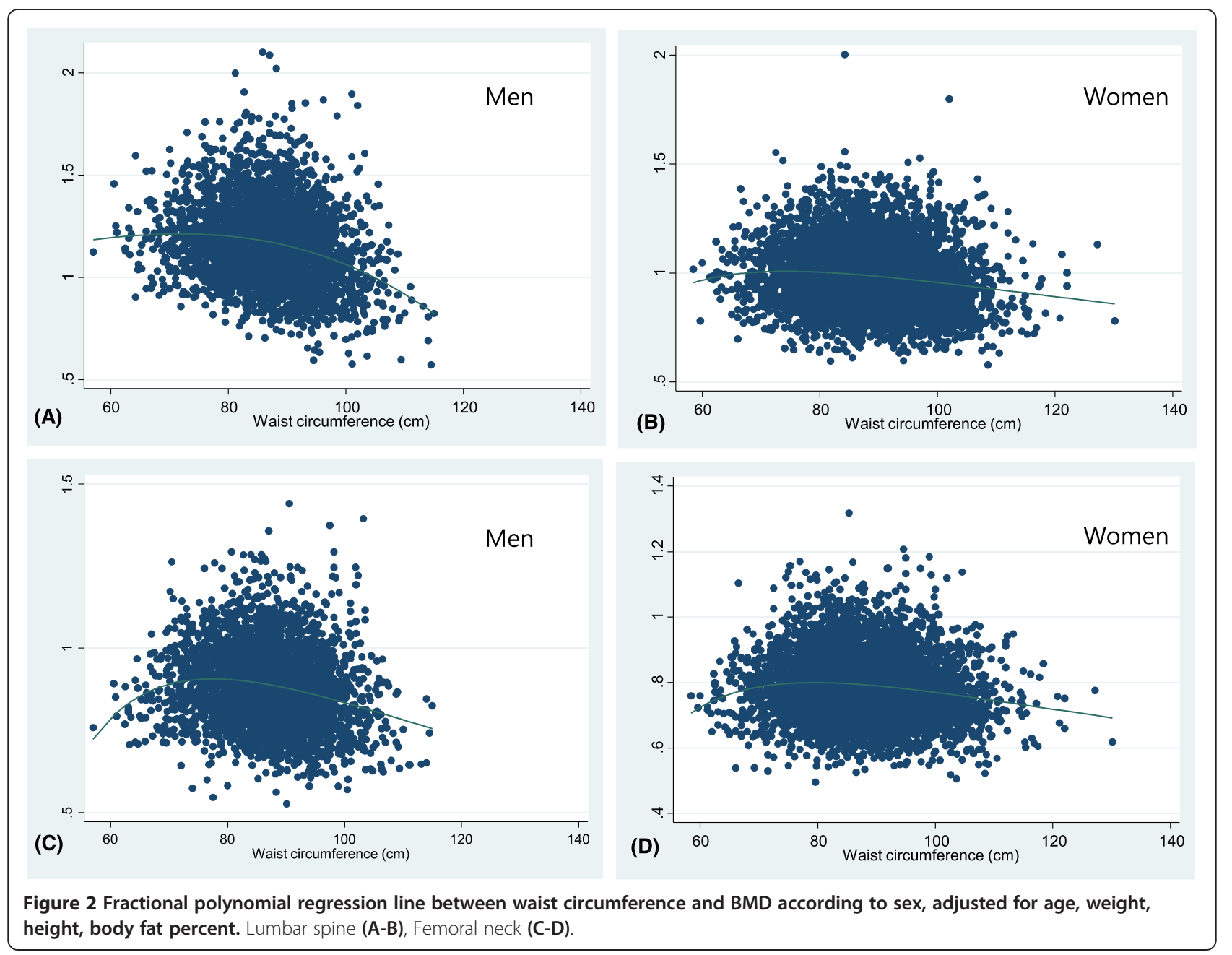

Table 2 Adjusted means of bone mineral density by quartiles of waist circumference

\begin{tabular}{|c|c|c|c|c|c|c|c|}
\hline \multicolumn{8}{|c|}{ Quartile of waist circumference } \\
\hline & & $1 \mathrm{st}$ & 2nd & $3 \mathrm{rd}$ & 4th & $P$ for trend & $P$ for interaction \\
\hline \multicolumn{2}{|c|}{ Number (men/women) } & $898 / 1346$ & $894 / 1355$ & $896 / 1345$ & $904 / 1343$ & & \\
\hline \multicolumn{2}{|c|}{ Range (men/women, cm) } & $(57.0-82.2) /(58.4-82.5)$ & $(82.3-87.2) /(82.6-88.6)$ & $(87.3-92.1) /(88.7-94.2)$ & $(92.2-115.0) /(94.3-130.1)$ & & \\
\hline \multirow[t]{6}{*}{ Model 1} & Lumbar spine & & & & & & \\
\hline & Men & $1.189 \pm 0.009$ & $1.185 \pm 0.006$ & $1.153 \pm 0.006$ & $1.117 \pm 0.009$ & $<0.001$ & \\
\hline & Women & $0.999 \pm 0.005$ & $0.996 \pm 0.004$ & $0.977 \pm 0.004$ & $0.967 \pm 0.005$ & $<0.001$ & 0.001 \\
\hline & Femoral neck & & & & & & \\
\hline & Men & $0.903 \pm 0.005$ & $0.896 \pm 0.004$ & $0.875 \pm 0.004$ & $0.851 \pm 0.005$ & $<0.001$ & \\
\hline & Women & $0.797 \pm 0.003$ & $0.794 \pm 0.003$ & $0.787 \pm 0.003$ & $0.772 \pm 0.003$ & $<0.001$ & 0.008 \\
\hline \multirow[t]{6}{*}{ Model 2} & Lumbar spine & & & & & & \\
\hline & Men & $1.185 \pm 0.009$ & $1.184 \pm 0.006$ & $1.154 \pm 0.006$ & $1.120 \pm 0.009$ & $<0.001$ & \\
\hline & Women & $0.998 \pm 0.005$ & $0.996 \pm 0.004$ & $0.978 \pm 0.004$ & $0.968 \pm 0.005$ & $<0.001$ & 0.001 \\
\hline & Femoral neck & & & & & & \\
\hline & Men & $0.896 \pm 0.005$ & $0.895 \pm 0.004$ & $0.877 \pm 0.004$ & $0.856 \pm 0.005$ & $<0.001$ & \\
\hline & Women & $0.794 \pm 0.003$ & $0.794 \pm 0.003$ & $0.788 \pm 0.003$ & $0.774 \pm 0.003$ & $<0.001$ & 0.016 \\
\hline
\end{tabular}

Values are mean difference with 1st quartile group in $\mathrm{g} / \mathrm{cm}^{2}$ with $95 \%$ confidence interval, adjusted age, height, weight, and regular exercise (model 1) or age, height, weight, regular exercise and body fat percent (model 2). 
Table 3 Linear association between obesity-related phenotypes and bone mineral density

\begin{tabular}{|c|c|c|c|c|c|c|c|}
\hline & & & \multicolumn{2}{|l|}{ Unadjusted } & \multicolumn{3}{|c|}{ Adjusted* } \\
\hline & & & Coefficients & p-value & Coefficients & Standardized coefficients & p-value \\
\hline \multirow[t]{8}{*}{ Lumbar spine BMD } & Men & Waist circumference $(10 \mathrm{~cm})$ & $0.075 \pm 0.004$ & $<0.001$ & $-0.051 \pm 0.008$ & -0.198 & $<0.001$ \\
\hline & & Waist/hip ratio & $0.575 \pm 0.062$ & $<0.001$ & $-0.203 \pm 0.070$ & -0.054 & 0.004 \\
\hline & & Body fat percent (10\%) & $0.072 \pm 0.006$ & $<0.001$ & $-0.024 \pm 0.008$ & -0.067 & 0.003 \\
\hline & & Fat mass (10 kg) & $0.111 \pm 0.006$ & $<0.001$ & $-0.049 \pm 0.012$ & -0.132 & $<0.001$ \\
\hline & Women & Waist circumference $(10 \mathrm{~cm})$ & $0.021 \pm 0.003$ & $<0.001$ & $-0.020 \pm 0.004$ & -0.108 & $<0.001$ \\
\hline & & Waist/hip ratio & $-0.113 \pm 0.031$ & $<0.001$ & $-0.103 \pm 0.031$ & -0.045 & 0.001 \\
\hline & & Body fat percent (10\%) & $0.031 \pm 0.004$ & $<0.001$ & $-0.016 \pm 0.006$ & -0.054 & 0.007 \\
\hline & & Fat mass (10 kg) & $0.073 \pm 0.004$ & $<0.001$ & $-0.041 \pm 0.010$ & -0.138 & $<0.001$ \\
\hline \multirow[t]{8}{*}{ Femoral neck BMD } & Men & Waist circumference $(10 \mathrm{~cm})$ & $0.044 \pm 0.003$ & $<0.001$ & $-0.028 \pm 0.005$ & -0.170 & 0.035 \\
\hline & & Waist/hip ratio & $0.236 \pm 0.040$ & $<0.001$ & $-0.136 \pm 0.043$ & -0.056 & 0.002 \\
\hline & & Body fat percent (10\%) & $0.023 \pm 0.004$ & $<0.001$ & $-0.031 \pm 0.005$ & -0.137 & $<0.001$ \\
\hline & & Fat mass (10 kg) & $0.057 \pm 0.004$ & $<0.001$ & $-0.053 \pm 0.007$ & -0.223 & $<0.001$ \\
\hline & Women & Waist circumference $(10 \mathrm{~cm})$ & $0.005 \pm 0.002$ & 0.003 & $-0.012 \pm 0.002$ & -0.085 & 0.030 \\
\hline & & Waist/hip ratio & $-0.209 \pm 0.022$ & $<0.001$ & $-0.082 \pm 0.020$ & -0.050 & $<0.001$ \\
\hline & & Body fat percent (10\%) & $0.003 \pm 0.003$ & 0.0349 & $-0.021 \pm 0.004$ & -0.103 & $<0.001$ \\
\hline & & Fat mass (10 kg) & $0.036 \pm 0.003$ & $<0.001$ & $-0.052 \pm 0.007$ & -0.242 & $<0.001$ \\
\hline
\end{tabular}

*Unstandardized regression coefficients and standardized regression coefficients were calculated by using a multiple linear regression adjusting for age, height, weight, and regular exercise separately for each obesity-related phenotype.

between BMD and VAT and abdominal subcutaneous (SAT) adipose tissue in African-American and white males and females, whereas another study found a positive relationship between fat mass femoral neck BMD in white and black females, but no significant relationship in males [43]. In contrast, Kim et al. [28] found a negative association between waist circumference and femoral neck BMD in males and females, particularly in males, which is consistent with our findings.

Our study had several strengths. To our knowledge, it is the largest investigation of the association between waist circumference and BMD in community-dwelling individuals $(n=8982)$. Furthermore, we controlled for multiple covariates and the study population included both males and females. Our study also had several limitations. First, we did not examine various inflammatory markers and diet information. Second, we did not examine the abdominal adiposity distribution, we could not determine the individual associations of VAT and SAT with BMD. Third, the cross-sectional design of our study did not allow us to establish causal relationships. Further investigation should examine the biological link between inflammation and waist circumference in the progression of osteoporosis.

\section{Conclusions}

Waist circumference is independently and inversely associated with BMD when the body components are controlled for, suggesting that waist circumference is a potential predictor of osteoporosis in middle-aged and older Korean males and postmenopausal females.

\section{Competing interests}

The authors declare that they have no competing interests.

\section{Authors' contributions}

MHS planned the study design and performed the data analysis. LHC participated in the study design and drafted the manuscript. SSK, JAR and JSC participated in the study design. YHL and HSN participated in the epidemiology survey and data collection. SKJ, KSP, SWC and SYR carried out physical examinations and collected data. All authors read and approved the final manuscript.

\section{Acknowledgments}

This study was supported by Research Institute of Medical Sciences, Chonnam National University. This study was partially supported by the Health Promotion Fund, Ministry of Health \&Welfare, Republic of Korea (07-27)

\section{Author details}

${ }^{1}$ Department of Preventive Medicine, Qingdao University Medical College, Qingdao, China. ${ }^{2}$ Department of Preventive Medicine, Chonnam National University Medical School, 5 hak-dong, Dong-gu, 501-746 Gwangju City, South Korea. ${ }^{3}$ Jeonnam Regional Cancer Center, Chonnam National University Medical School, Hwasun Hospital, Hwasun, Republic of Korea. ${ }^{4}$ Department of Preventive Medicine \& Institute of Wonkwang Medical Science, Wonkwang University College of Medicine, Iksan, Republic of Korea. ${ }^{5}$ Department of Preventive Medicine, Chungnam National University Medical School, Daejeon, Republic of Korea. ${ }^{6}$ Department of Neurology \& Research Institute of Clinical Medicine, Chonbuk National University-Biomedical Research Institute of Chonbuk National University Hospital, Jeonju, Republic of Korea. ${ }^{7}$ Department of Preventive Medicine, Seonam University College of Medicine, Namwon, Republic of Korea. ${ }^{8}$ Department of Preventive Medicine, Chosun University Medical School, Gwangju, Republic of Korea.

Received: 11 May 2014 Accepted: 26 September 2014

Published: 2 October 2014 


\section{References}

1. Han TS, van Leer EM, Seidell JC, Lean ME: Waist circumference action levels in the identification of cardiovascular risk factors: prevalence study in a random sample. BMJ 1995, 311(7017):1401-1405.

2. Savva SC, Tornaritis M, Savva ME, Kourides Y, Panagi A, Silikiotou N, Georgiou C, Kafatos A: Waist circumference and waist-to-height ratio are better predictors of cardiovascular disease risk factors in children than body mass index. Int J Obes Relat Metab Disord 2000, 24(11):1453-1458.

3. Zhu S, Heymsfield SB, Toyoshima H, Wang Z, Pietrobelli A, Heshka S: Race-ethnicity-specific waist circumference cutoffs for identifying cardiovascular disease risk factors. Am J Clin Nutr 2005, 81(2):409-415.

4. Zhang C, Rexrode KM, van Dam RM, Li TY, Hu FB: Abdominal obesity and the risk of all-cause, cardiovascular, and cancer mortality: sixteen years of follow-up in US women. Circulation 2008, 117(13):1658-1667.

5. Efstathiou JA, Bae K, Shipley WU, Hanks GE, Pilepich MV, Sandler HM, Smith MR: Obesity and mortality in men with locally advanced prostate cancer: analysis of RTOG 85-31. Cancer 2007, 110(12):2691-2699.

6. Dal Maso L, Zucchetto A, Talamini R, Serraino D, Stocco CF, Vercelli M, Falcini $F$, Franceschi S: Effect of obesity and other lifestyle factors on mortality in women with breast cancer. Int I Cancer 2008, 123(9):2188-2194.

7. Connelly PW, Hanley AJ, Harris SB, Hegele RA, Zinman B: Relation of waist circumference and glycemic status to C-reactive protein in the Sandy Lake Oji-Cree. Int J Obes Relat Metab Disord 2003, 27(3):347-354.

8. Forouhi NG, Sattar N, McKeigue PM: Relation of C-reactive protein to body fat distribution and features of the metabolic syndrome in Europeans and South Asians. Int J Obes Relat Metab Disord 2001, 25(9):1327-1331.

9. Pannacciulli N, Cantatore FP, Minenna A, Bellacicco M, Giorgino R, De Pergola G: C-reactive protein is independently associated with total body fat, central fat, and insulin resistance in adult women. Int I Obes Relat Metab Disord 2001, 25(10):1416-1420.

10. Pfeilschifter J: Role of cytokines in postmenopausal bone loss. Curr Osteoporos Rep 2003, 1(2):53-58.

11. Siggelkow H, Eidner T, Lehmann G, Viereck V, Raddatz D, Munzel U, Hein G, Hufner M: Cytokines, osteoprotegerin, and RANKL in vitro and histomorphometric indices of bone turnover in patients with different bone diseases. J Bone Miner Res 2003, 18(3):529-538.

12. Bultink IE, Lems WF, Kostense PJ, Dijkmans BA, Voskuyl AE: Prevalence of and risk factors for low bone mineral density and vertebral fractures in patients with systemic lupus erythematosus. Arthritis Rheum 2005, 52(7):2044-2050

13. Mikuls TR, Saag KG, Curtis J, Bridges SL Jr, Alarcon GS, Westfall AO, Lim SS, Smith EA, Jonas BL, Moreland LW: Prevalence of osteoporosis and osteopenia among African Americans with early rheumatoid arthritis: the impact of ethnic-specific normative data. J Natl Med Assoc 2005, 97(8):1155-1160

14. Mitra D, Elvins DM, Speden DJ, Collins AJ: The prevalence of vertebral fractures in mild ankylosing spondylitis and their relationship to bone mineral density. Rheumatology (Oxford) 2000, 39(1):85-89.

15. Albala C, Yanez M, Devoto E, Sostin C, Zeballos L, Santos JL: Obesity as a protective factor for postmenopausal osteoporosis. Int I Obes Relat Metab Disord 1996, 20(11):1027-1032.

16. Felson DT, Zhang Y, Hannan MT, Anderson JJ: Effects of weight and body mass index on bone mineral density in men and women: the Framingham study. J Bone Miner Res 1993, 8(5):567-573.

17. Ravn P, Cizza G, Bjarnason NH, Thompson D, Daley M, Wasnich RD, McClung M, Hosking D, Yates AJ, Christiansen C: Low body mass index is an important risk factor for low bone mass and increased bone loss in early postmenopausal women. Early Postmenopausal Intervention Cohort (EPIC) study group. J Bone Miner Res 1999, 14(9):1622-1627.

18. Kim CJ, Oh KW, Rhee EJ, Kim KH, Jo SK, Jung CH, Won JC, Park CY, Lee WY Park SW, Kim SW: Relationship between body composition and bone mineral density (BMD) in perimenopausal Korean women. Clin Endocrinol (Oxf) 2009, 71(1):18-26.

19. Seo HJ, Kim SG, Kim CS: Risk factors for bone mineral density at the calcaneus in 40-59 year-old male workers: a cross-sectional study in Korea. BMC Public Health 2008, 8:253.

20. Jankowska EA, Rogucka E, Medras M: Are general obesity and visceral adiposity in men linked to reduced bone mineral content resulting from normal ageing? A population-based study. Andrologia 2001, 33(6):384-389.
21. Kim JH, Choi HJ, Kim MJ, Shin CS, Cho NH: Fat mass is negatively associated with bone mineral content in Koreans. Osteoporos Int 2012, 23(7):2009-2016.

22. Tseng YH, Huang KC, Liu ML, Shu WT, Sheu WH: Association between metabolic syndrome (MS) and bone mineral loss: a cross-sectional study in Puli Township in Taiwan. Arch Gerontol Geriatr 2009. 49(Suppl 2):S37-S40.

23. von Muhlen D, Safii S, Jassal SK, Svartberg J, Barrett-Connor E: Associations between the metabolic syndrome and bone health in older men and women: the Rancho Bernardo Study. Osteoporos Int 2007, 18(10):1337-1344.

24. Hernandez JL, Olmos JM, Pariente E, Martinez J, Valero C, Garcia-Velasco P, Nan D, Llorca J, Gonzalez-Macias J: Metabolic syndrome and bone metabolism: the Camargo Cohort study. Menopause 2010, 17(5):955-961.

25. Kinjo M, Setoguchi S, Solomon DH: Bone mineral density in adults with the metabolic syndrome: analysis in a population-based U.S. sample. J Clin Endocrinol Metab 2007, 92(11):4161-4164.

26. Szulc P, Varennes A, Delmas PD, Goudable J, Chapurlat R: Men with metabolic syndrome have lower bone mineral density but lower fracture risk-the MINOS study. J Bone Miner Res 2010, 25(6):1446-1454.

27. Kim KC, Shin DH, Lee SY, Im JA, Lee DC: Relation between obesity and bone mineral density and vertebral fractures in Korean postmenopausal women. Yonsei Med J 2010, 51(6):857-863.

28. Kim HY, Choe JW, Kim HK, Bae SJ, Kim BJ, Lee SH, Koh JM, Han KO, Park HM, Kim GS: Negative association between metabolic syndrome and bone mineral density in Koreans, especially in men. Calcif Tissue Int 2010, 86(5):350-358.

29. Kweon SS, Shin MH, Jeong SK, Nam HS, Lee YH, Park KS, Ryu SY, Choi SW, Kim BH, Rhee JA, Zheng W, Choi JS: Cohort Profile: The Namwon Study and the Dong-gu Study. Int J Epidemiol 2014, 43(2):558-567.

30. Tarquini B, Navari N, Perfetto F, Piluso A, Romano S, Tarquini R: Evidence for bone mass and body fat distribution relationship in postmenopausal obese women. Arch Gerontol Geriatr 1997, 24(1):15-21.

31. Bhupathiraju SN, Dawson-Hughes B, Hannan MT, Lichtenstein AH, Tucker KL Centrally located body fat is associated with lower bone mineral density in older Puerto Rican adults. Am J Clin Nutr 2011, 94(4):1063-1070.

32. Katzmarzyk PT, Barreira TV, Harrington DM, Staiano AE, Heymsfield SB, Gimble JM: Relationship between abdominal fat and bone mineral density in white and African American adults. Bone 2012, 50(2): $576-579$

33. Warming L, Ravn P, Christiansen C: Visceral fat is more important than peripheral fat for endometrial thickness and bone mass in healthy postmenopausal women. Am J Obstet Gynecol 2003, 188(2):349-353.

34. Marwaha RK, Garg MK, Tandon N, Mehan N, Sastry A, Bhadra K: Relationship of body fat and its distribution with bone mineral density in Indian population. J Clin Densitom 2013, 16(3):353-359.

35. Yoo HJ, Park MS, Yang SJ, Kim TN, Lim KI, Kang HJ, Song W, Baik SH, Choi DS, Choi KM: The differential relationship between fat mass and bone mineral density by gender and menopausal status. J Bone Miner Metab 2012, 30(1):47-53.

36. Kim T, Park S, Pak YS, Lee S, Lee EH: Association between metabolic syndrome and bone mineral density in Korea: the Fourth Korea National Health and Nutrition Examination Survey (KNHANES IV), 2008. J Bone Miner Metab 2013, 31(6):652-662.

37. Zhao L, Liu YJ, Liu PY, Hamilton J, Recker RR, Deng HW: Relationship of obesity with osteoporosis. J Clin Endocrinol Metab 2007, 92(5):1640-1646.

38. Hsu YH, Venners SA, Terwedow HA, Feng Y, Niu T, Li Z, Laird N, Brain JD, Cummings SR, Bouxsein ML, Rosen CJ, Xu X: Relation of body composition, fat mass, and serum lipids to osteoporotic fractures and bone mineral density in Chinese men and women. Am J Clin Nutr 2006, 83(1):146-154.

39. Lekamwasam S, Weerarathna T, Rodrigo M, Arachchi WK, Munidasa D: Association between bone mineral density, lean mass, and fat mass among healthy middle-aged premenopausal women: a cross-sectional study in southern Sri Lanka. J Bone Miner Metab 2009, 27(1):83-88.

40. Aghaei Meybodi H, Hemmat-Abadi M, Heshmat R, Rezaei Homami M, Madani S, Ebrahimi M, Adibi H, Larijani B: Association between anthropometric measures and bone mineral density: population-based study. Iran J Public Health 2011, 40(2):18-24.

41. Campos RM, de Piano A, da Silva PL, Carnier J, Sanches PL, Corgosinho FC, Masquio DC, Lazaretti-Castro M, Oyama LM, Nascimento CM, Tock L, de Mello MT, Tufik S, Dâmaso AR: The role of pro/anti-inflammatory 
adipokines on bone metabolism in NAFLD obese adolescents: effects of long-term interdisciplinary therapy. Endocrine 2012, 42(1):146-156.

42. Smith BJ, Lerner MR, Bu SY, Lucas EA, Hanas JS, Lightfoot SA, Postier RG, Bronze MS, Brackett DJ: Systemic bone loss and induction of coronary vessel disease in a rat model of chronic inflammation. Bone 2006, 38(3):378-386

43. Taaffe DR, Cauley JA, Danielson M, Nevitt MC, Lang TF, Bauer DC, Harris TB: Race and sex effects on the association between muscle strength, soft tissue, and bone mineral density in healthy elders: the Health, Aging, and Body Composition Study. J Bone Miner Res 2001, 16(7):1343-1352.

doi:10.1186/1471-2474-15-326

Cite this article as: Cui et al:: Sex-related differences in the association between waist circumference and bone mineral density in a Korean population. BMC Musculoskeletal Disorders 2014 15:326.

\section{Submit your next manuscript to BioMed Central and take full advantage of:}

- Convenient online submission

- Thorough peer review

- No space constraints or color figure charges

- Immediate publication on acceptance

- Inclusion in PubMed, CAS, Scopus and Google Scholar

- Research which is freely available for redistribution 